Brief Report

\title{
Covid-19 and the Subsequent Lockdown Modified Dietary Habits of Almost Half the Population in an Italian Sample
}

\author{
Federico Scarmozzino ${ }^{1}$ and Francesco Visioli ${ }^{1,2, *(D)}$ \\ 1 Department of Molecular Medicine, University of Padova, Viale G. Colombo 3, 35121 Padova, Italy; \\ federico.scarmozzino@studenti.unipd.it \\ 2 IMDEA-Food, CEI UAM + CSIC, 28049 Madrid, Spain \\ * Correspondence: francesco.visioli@unipd.it
}

Received: 21 April 2020; Accepted: 18 May 2020; Published: 25 May 2020

check for updates

\begin{abstract}
The Covid-19 pandemic led to lockdowns in several parts of the world and, hence, changed some daily habits, including social interactions, the ability to perform sports, and - possibly-diet. The Italian government established and promulgated lockdown policies on 9 March 2020. We aim at assessing the effects of Covid-19-induced confinement policies on self-reported food consumption of self-selected Italians by means of a questionnaire that was created and diffused by the Internet. Nearly half, i.e., $49.6 \%$ of responders did not substantially modify their diet during the lockdown; however, $46.1 \%$ of them reported that they were eating more during confinement, and $19.5 \%$ gained weight. In particular, we report an increase in "comfort food" consumption, notably chocolate, ice-cream, and desserts (42.5\%) and salty snacks (23.5\%). In addition, $42.7 \%$ percent of this cohort attributed this increase to higher anxiety levels. Related to this, $36.8 \%$ of responders reported a decrease in alcohol consumption, even though $10.1 \%$ of them reported an increase. Interestingly, $21.2 \%$ of responders increased their consumption of fresh fruit and vegetables. Only $33.5 \%$ of those who declared decreased consumption attributed this change of diet to lower availability and ease of purchasing such items. Equally interesting, over half of responders, i.e., $56.2 \%$, admitted that fruit and vegetables did not appeal to them while in lockdown. Purchases of ready-made meals were reduced by nearly $50 \%$. Future large-scale similar studies should be undertaken worldwide and will help public health authorities shape their reactions to future, unavoidable pandemics.
\end{abstract}

Keywords: Covid-19; diet; dietary habits; lockdown; food availability

\section{Introduction}

The Covid-19 pandemic led to lockdowns in several parts of the world and, hence, changed several daily habits, including social interactions, the ability to perform sports, and-possibly-diet. Diet being one of the foremost contributors to health [1], it is conceivable that a situation in which food availability, access to it, and a shift from eating out to mandatory in-house consumption could have change the dietary profiles of several people. However, to the best of our knowledge, this issue has never been explored.

One of the most interesting and novel proxies of healthy diets is food, namely, produce availability [2]. Interesting research is suggesting that the easier it is to purchase healthful foods, the easier it is to follow appropriate diets [3]. Food accessibility may be impaired during confinements, which could easily impact the overall diet quality. Moreover, the impending possibility of job losses, reduced incomes, and uncertainties regarding the future might speculatively lead some people to reduce their expenditures, including those for food. 
Finally, lockdowns greatly reduce the amount of physical activity, sport, exercise, creating vicious cycles by which sub-optimal diets increase the noxious health effects of sedentarism [4]. This situation is exacerbated by severe restraints, such as those that are commonplace in prisons, where detainees often experience psychological distress [5]. Indeed, some authors [6] are proposing prospective neuropsychiatric monitoring of individuals exposed to SARS-CoV-2 at various points in the life course. Even though the neuropsychiatric burden of this pandemic is currently unknown, it is likely to be significant [6]. The relation between diet and mood or psychiatric status is mutual. On the one hand, some diets are being proposed as having positive effects on mood [7], possibly because they provide (poly)phenols (see below) [8], vitamins, and, e.g., tryptophan for serotonin production [9]. On the other hand, dietary choices are strongly influenced by psychological factors [10] in addition to the environment where we live or our beliefs [11]. In short, it is conceivable that lockdowns bring about dietary changes whose long-term health effects are unknown and worth investigating.

The Italian government established and promulgated lockdown policies on 9 March 2020. We aimed at assessing the effects of Covid-19-induced confinement policies on self-reported food consumption of self-selected Italians by means of a questionnaire that was created and diffused by the Internet.

\section{Methods}

On 3 April 2020, we created an anonymous questionnaire (in Italian, retrievable at https://clikka. net/(flBP) that aimed at assessing the most popular eating habits of Italians. Anonymity was guaranteed by the platform, and there was no way to link participants' emails with responses. We distributed the questionnaire via social media, e.g., Linkedin, and published a link to it in a very popular Italian agriculture magazine (Olio Officina). Also, students from the Medical School of the University of Padova distributed the survey via personal contacts. Of course, participants were not rewarded, and we could not identify them, as mentioned above. We closed the survey and stopped collecting data on 15 April, when 1932 surveys were filled out. We then translated all questions and have provided them as Supplementary Materials.

We analyzed data immediately thereafter.

\section{Results}

The entire dataset can be found in Figure S1. Here, we would like to focus on the most relevant results. Nearly half, i.e., $49.6 \%$, of responders did not substantially modify their diet during the lockdown (Figure 1A); however, $52.9 \%$ of them reported that they were eating more during confinement (Figure 1B) and 19.5\% gained weight (Figure 1C). In particular, we report an increase in "comfort food" consumption, notably chocolate, ice-cream, and desserts ( $42.5 \%$ ) and salty snacks (23.5\%) (Figure 2A,B). Furthermore, $42.7 \%$ percent of this cohort attributed this increase to higher anxiety levels. Related to this, $36.8 \%$ of responders reported a decrease in alcohol consumption (Figure 2C), even though $10.1 \%$ of them reported an increase.

Interestingly, $21.2 \%$ of responders increased their consumption of fresh fruit and vegetables (Figure 3A). Only 33.5\% of those who declared decreased consumption attributed this change of diet to lower availability and ease to purchase such items (Figure 3B). Equally interesting, over half of responders, i.e., $56.2 \%$, admitted that fruit and vegetables did not appeal to them while in lockdown (Figure 3B).

Purchases of ready-made meals were reduced by nearly 50\% (Figure S1). 
What is the main reason for your diet variations during the lockdown?

A

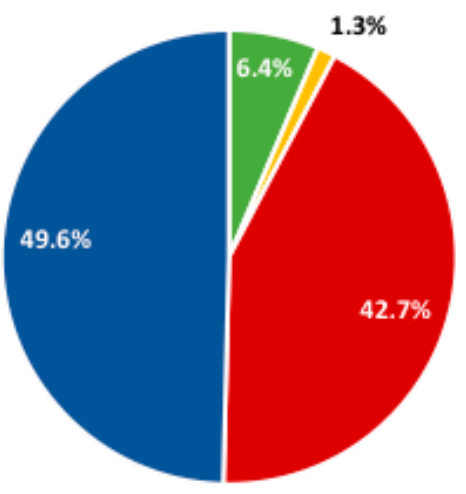

$$
\begin{aligned}
& \text { - The greater difficulty to } \\
& \text { find certain products } \\
& \text { \# The increased price of } \\
& \text { certain products } \\
& \text { - The increased } \\
& \text { stress/anxiety/boredom } \\
& \text { during the quarantine } \\
& \text { - I haven't changed my diet } \\
& \text { in a relevant way }
\end{aligned}
$$

Would you say that you are eating more during this lockdown?

B

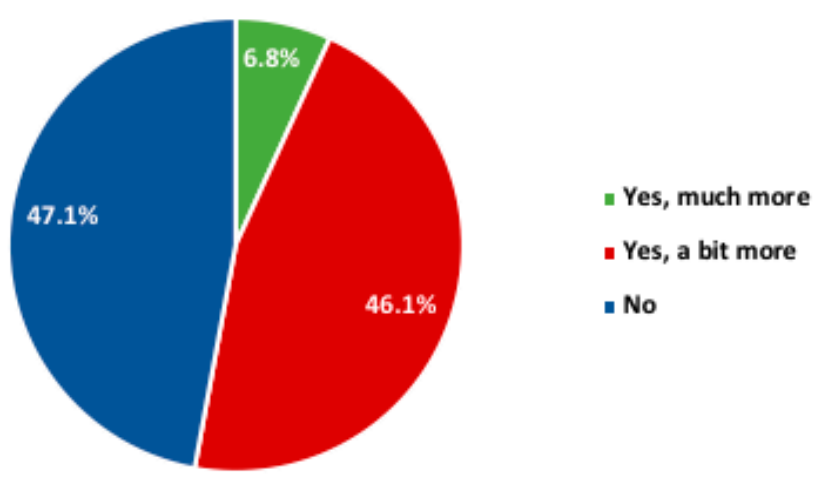

C

Have you gained weight during the lockdown?

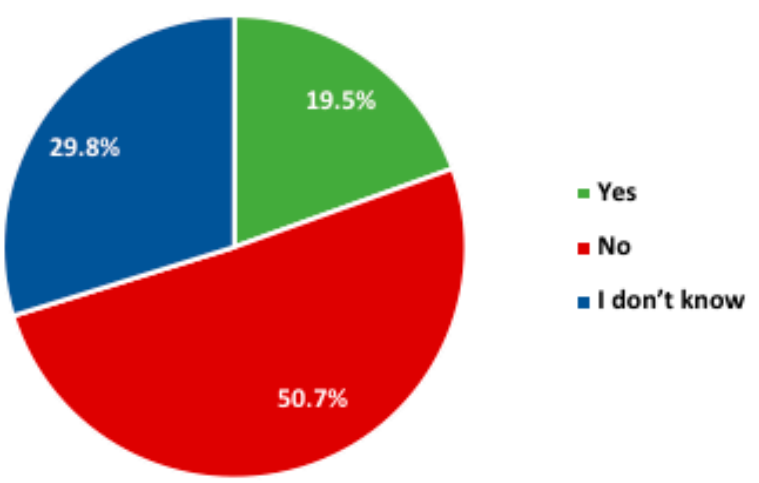

Figure 1. Overall reported dietary changes during the lockdown. 
Have you changed your consumption of other kinds of sweet food (chocolate, spreads, cakes, ice creams) during the lockdown?

A

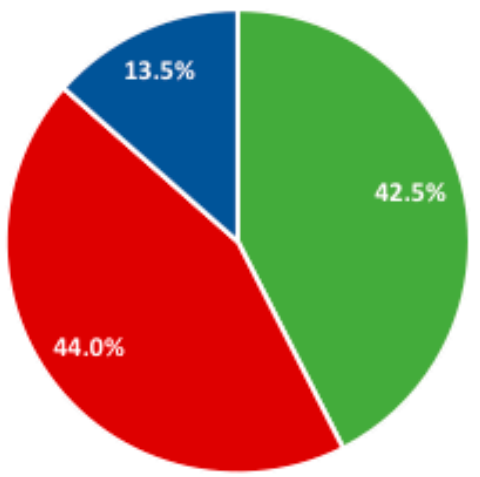

॥ Yes, 1 increased it

I have been consuming more or less the usual amount

- Yes, I decreased it

Have you changed your consumption of sweet or salty snacks during the lockdown?

B

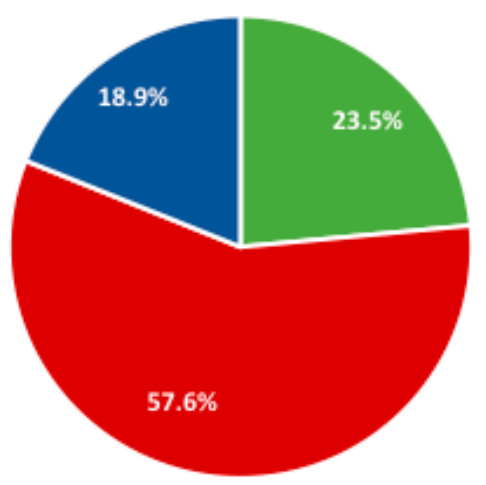

- Yes, I increased it

- No, I have been consuming more or less the usual amount

- Yes, I decreased it

Have you changed your consumption of wine, beer,

C liquors during the lockdown?

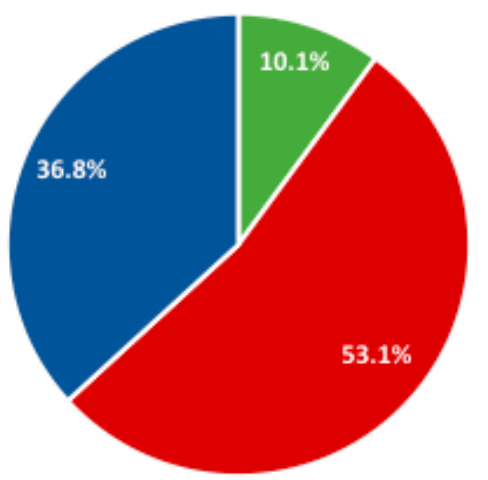

- Yes, 1 increased it

- No, I have been consuming more or less the usual amount

- Yes, I decreased it

Figure 2. Reported changes in comfort food and alcohol consumption during the lockdown. 


\section{Have you changed your fresh fruit and vegetables consumption during the lockdown?}

A
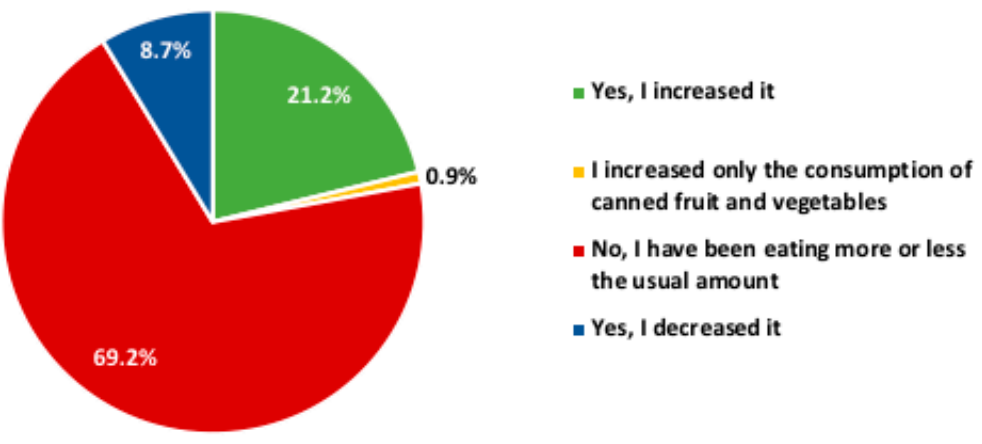

\section{If you decreased consumption, why?}

\section{B}
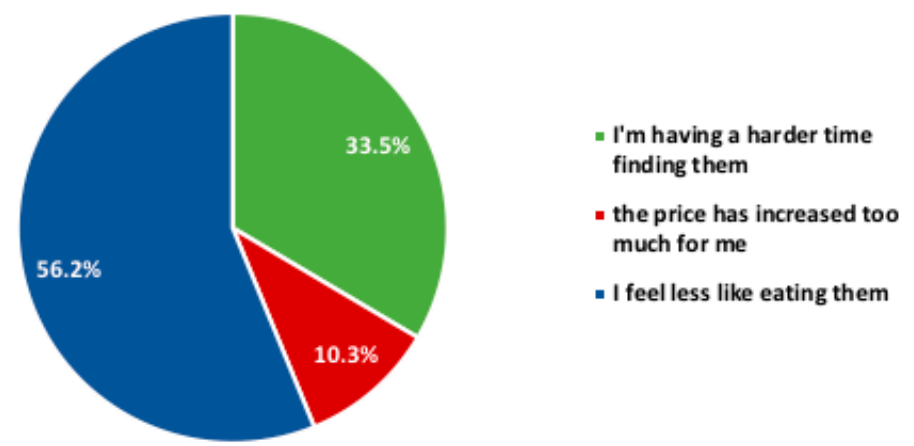

Figure 3. Reported produce consumption during the lockdown.

\section{Discussion}

We surveyed the dietary habits of an Italian sample, via distribution of a questionnaire, during the Covid-19 pandemic. Our results indicate that Covid-19 and the subsequent lockdown induced about half the respondents to eat more. However, a relevant, i.e., $21.2 \%$ of responders upped their consumption of fresh fruit and vegetables. This is noteworthy in terms of micronutrient intake, which is particularly important in the elderly and in the population at large [12]. In terms of micronutrients, the lay public's wisdom holds it that some vitamins, namely $\mathrm{C}$ and $\mathrm{D}$, help fight viral infections. To date, however, the evidence is weak [13,14], and many more controlled trials should be performed. In any case, whether the protective effects of fruit and vegetables are due to their vitamins and other micro-nutrients [15] or fiber content or to their contribution to the improvement of the overall dietary pattern increased consumption should be viewed as positive.

In our sample, the majority, i.e., $64.8 \%$ of respondents did not remarkably change their habits of fish consumption (Figure S1), which was in line with the international guidelines for over $30 \%$ of the cohort (Figure S1) [16]. It is worth noting that the immunomodulatory effects of omega 3 fatty acids have never been explored in humans [17]. However, human immune cells are typically rich in arachidonic acid and poor in EPA and DHA [17]. In addition, the phospholipids of immune-competent cells (such as lymph node or splenic lymphocytes or peritoneal macrophages) taken from rodents maintained on normal laboratory chow typically contain $15-20 \%$ of fatty acids as arachidonic acid and very little very long-chain $\mathrm{n}-3$ fatty acids [18]. The bulk phospholipid of human immune cells (e.g., neutrophils, lymphocytes, monocytes) isolated from subjects of consuming typical Western diets also contains about $20 \%$ of arachidonic acid (as a percentage of fatty acids), about $1 \%$ EPA and 
about 2.5\% DHA [18]. By modulating lipid raft structure and function and membrane trafficking, we could theoretically reduce the inordinate response of the immune system and lessen the noxious consequences of inflammation [19]. In summary, even though the current human evidence does not allow recommending fish oil supplements, the advice to frequently eat oily fish should be reinforced, albeit the availability of marine products during lockdowns might be lower.

Some people, i.e., $8.7 \%$, decreased fruit and vegetable use and attributed this chance to difficulties in finding open grocery stores in their neighborhood, corroborating the aforementioned findings of Bilal et al. [3] and calling for public health intervention. Alas, half of the participants increased consumption of comfort foods, be them sweet or salty. Whether this is due to the induction of a vicious cycle is still a matter of debate, but there is a clear relation between anxiety levels and cravings/hunger pangs [20]. This agrees with very recent evidence showing that protein consumption is more stable than carbohydrate consumption, suggesting biological control mechanism(s) tightly regulate protein intake and, consequently, influence intake of other macronutrients and food constituents [21]. Conceivably, the adoption of stress-relief techniques such as indoor exercise, meditation, and yoga, might lessen this untoward effect of confinement and should be promoted by health authorities [22].

One issue worth discussing in the $36.8 \%$ decrease in alcohol consumption. Alcohol use is a matter of concern by public health authorities; however, it is conceivable that this shift simply reflects the mere substitution of "social drinking", i.e., alcohol consumption in bars and restaurants with in-house use. In other words, maybe people do not take alcohol use outside of their households into consideration when they compute and report their total consumption. Given the notorious under-reporting of alcohol consumption [23], further investigations should address and elucidate this important issue.

The self-reported decrease in alcohol use was mirrored by an increase in tea, coffee, and herbal tea consumption. Conceivably, the forced creation of a limited space in which to work and live conflated some habits of taking breaks and self-reward. In terms of health effects, tea [24], coffee [25], and herbal teas are very rich in (poly)phenols, namely flavonoids. Plenty of epidemiological studies report inverse associations between (poly)phenol intake and risk of several degenerative diseases, mainly cardiovascular disease, cancer, and neurodegeneration. Intervention trials are not univocal in their conclusions [26], but this result should be view as a positive one, and, hopefully, this habit will be maintained once lockdowns are lifted.

Another interesting result is the decrease in ready-made meals' purchase, which was halved by the lockdown. Conceivably (and confirmed by anecdotal evidence of yeast and flour scarceness in supermarkets), instant "TV-dinners" are being replaced by hand-made dishes, including homemade bread and cakes. In addition, people have to endure long lines outside of supermarkets, which might have discouraged some to make trips and buy prepared meals, in keeping with the Bilal et al. [3] and Diez et al. [2] data. It should be remembered that part of the healthful effects of the Mediterranean diet is being attributed to the now-disappearing habit [27] of preparing most meals at home and sharing them with friends and family, thereby contributing to a pleasant social environment. We could speculate that if the newfound habit of home cooking is maintained after lockdowns are lifted, future improvement of dietary profiles could be envisaged [28]. As determinants of home cooking are more complex than simply possessing cooking skills, that potential positive associations between cooking, diet, and health require further confirmation [29].

This study has some strengths and limitations that should be acknowledged.

The first strength is that it is the first one of its kind and might provide some guidance to future, larger surveys. Ideally, such surveys should be distributed worldwide as they are easy to implement and yield a great deal of information. This is noteworthy in view of future, inescapable pandemics [30]. Also, we collected a large number of questionnaires, i.e., nearly 2000.

There are also several limitations. One is the young median age of our responder, which is mostly due to the dissemination manner (via social media) and to their familiarity with digital technologies. The latter, also known as the "digital divide" [31], is a frequent bias affecting Internet-based surveys and cannot currently be overcome [32]. Another limitation is the skewing in the geographical distribution 
of responders, which were $79 \%$ from the North-East. This is largely due to the fact that this study was initiated at the University of Padova and, therefore, broadly relied on local participants. Finally, we could not evaluate the impact of lockdown on different population sub-sets, sub-analyzing, e.g., by age, gender, household size, socio-economic status, or ethnicity, which would be important to better target future public health initiatives.

In conclusion, we report the first evidence of dietary habits' modifications during Covid-19 and associated lockdown. Hopefully, future large-scale similar studies will be undertaken worldwide and will help public health authorities shape their reactions to future, unavoidable pandemics.

Supplementary Materials: The following are available online at http://www.mdpi.com/2304-8158/9/5/675/s1, Figure S1: Results of the survey.

Author Contributions: F.V. conceived the study and built the questionnaire. F.S. and F.V. analyzed the data and wrote the paper. All authors have read and agreed to the published version of the manuscript.

Funding: This research received no external funding.

Acknowledgments: We thank those who disseminated the survey and those who filled out the questionnaires.

Conflicts of Interest: The authors declare no conflict of interest associated with this study.

\section{References}

1. Willett, W.; Rockstrom, J.; Loken, B.; Springmann, M.; Lang, T.; Vermeulen, S.; Garnett, T.; Tilman, D.; DeClerck, F.; Wood, A.; et al. Food in the Anthropocene: The EAT-Lancet Commission on healthy diets from sustainable food systems. Lancet 2019, 393, 447-492. [CrossRef]

2. Diez, J.; Bilal, U.; Franco, M. Unique features of the Mediterranean food environment: Implications for the prevention of chronic diseases Rh: Mediterranean food environments. Eur. J. Clin. Nutr. 2019, 72, 71-75. [CrossRef] [PubMed]

3. Bilal, U.; Jones-Smith, J.; Diez, J.; Lawrence, R.S.; Celentano, D.D.; Franco, M. Neighborhood social and economic change and retail food environment change in Madrid (Spain): The heart healthy hoods study. Health Place 2018, 51, 107-117. [CrossRef] [PubMed]

4. Fernandez-Sanjurjo, M.; de Gonzalo-Calvo, D.; Fernandez-Garcia, B.; Diez-Robles, S.; Martinez-Canal, A.; Olmedillas, H.; Davalos, A.; Iglesias-Gutierrez, E. Circulating microRNA as Emerging Biomarkers of Exercise. Exerc. Sport Sci. Rev. 2018, 46, 160-171. [CrossRef] [PubMed]

5. Lopez-Perez, B.; Deeprose, C.; Hanoch, Y. Prospective mental imagery and its link with anxiety and depression in prisoners. PLoS ONE 2018, 13, e0191551. [CrossRef]

6. Troyer, E.A.; Kohn, J.N.; Hong, S. Are we facing a crashing wave of neuropsychiatric sequelae of COVID-19? Neuropsychiatric symptoms and potential immunologic mechanisms. Brain. Behav. Immun. 2020. [CrossRef]

7. Arab, A.; Mehrabani, S.; Moradi, S.; Amani, R. The association between diet and mood: A systematic review of current literature. Psychiatry Res. 2019, 271, 428-437. [CrossRef]

8. Ammar, A.; Trabelsi, K.; Muller, P.; Bouaziz, B.; Boukhris, O.; Glenn, J.M.; Bott, N.; Driss, T.; Chtourou, H.; Muller, N.; et al. The Effect of (Poly)phenol-Rich Interventions on Cognitive Functions and Neuroprotective Measures in Healthy Aging Adults: A Systematic Review and Meta-Analysis. J. Clin. Med. 2020, 9, 835. [CrossRef]

9. Strasser, B.; Gostner, J.M.; Fuchs, D. Mood, food, and cognition: Role of tryptophan and serotonin. Curr. Opin. Clin. Nutr. Metab. Care 2016, 19, 55-61. [CrossRef]

10. Love, H.; Bhullar, N.; Schutte, N.S. Psychological aspects of diet: Development and validation of three measures assessing dietary goal-desire incongruence, motivation, and satisfaction with dietary behavior. Appetite 2019, 138, 223-232. [CrossRef]

11. Clark, M.A.; Springmann, M.; Hill, J.; Tilman, D. Multiple health and environmental impacts of foods. Proc. Natl. Acad. Sci. USA 2019, 116, 23357-23362. [CrossRef]

12. Visioli, F.; Hagen, T.M. Nutritional strategies for healthy cardiovascular aging: Focus on micronutrients. Pharmacol. Res. 2007, 55, 199-206. [CrossRef] [PubMed]

13. P, L.L.; Lamontagne, F. Vitamin C for the critically ill: Is the evidence strong enough? Nutrition 2019, 60, 185-190. [CrossRef] 
14. Calder, P.C.; Carr, A.C.; Gombart, A.F.; Eggersdorfer, M. Optimal Nutritional Status for a Well-Functioning Immune System Is an Important Factor to Protect against Viral Infections. Nutrients 2020, 12, 1181. [CrossRef]

15. Higdon, J.V.; Delage, B.; Williams, D.E.; Dashwood, R.H. Cruciferous vegetables and human cancer risk: Epidemiologic evidence and mechanistic basis. Pharmacol. Res. 2007, 55, 224-236. [CrossRef]

16. Bork, C.S.; Mortensen, L.T.; Hjelmgaard, K.; Schmidt, E.B. Marine n-3 fatty acids and CVD: New insights from recent follow-up studies and clinical supplementation trials. Proc. Nutr. Soc. 2020, 1-7. [CrossRef]

17. Calder, P.C. The relationship between the fatty acid composition of immune cells and their function. Prostaglandins Leukot Essent Fatty Acids 2008, 79, 101-108. [CrossRef]

18. Kew, S.; Mesa, M.D.; Tricon, S.; Buckley, R.; Minihane, A.M.; Yaqoob, P. Effects of oils rich in eicosapentaenoic and docosahexaenoic acids on immune cell composition and function in healthy humans. Am. J. Clin. Nutr. 2004, 79, 674-681. [CrossRef]

19. Fritsche, K. Fatty acids as modulators of the immune response. Annu. Rev. Nutr. 2006, 26, 45-73. [CrossRef]

20. Recio-Roman, A.; Recio-Menendez, M.; Roman-Gonzalez, M.V. Food Reward and Food Choice. An Inquiry Through The Liking and Wanting Model. Nutrients 2020, 12, 639. [CrossRef]

21. Lieberman, H.R.; Fulgoni, V.L.; Agarwal, S.; Pasiakos, S.M.; Berryman, C.E. Protein intake is more stable than carbohydrate or fat intake across various US demographic groups and international populations. Am. J. Clin. Nutr. 2020. [CrossRef]

22. Sampaio, C.V.; Lima, M.G.; Ladeia, A.M. Meditation, Health and Scientific Investigations: Review of the Literature. J. Relig. Health 2017, 56, 411-427. [CrossRef]

23. Zaridze, D.; Brennan, P.; Boreham, J.; Boroda, A.; Karpov, R.; Lazarev, A.; Konobeevskaya, I.; Igitov, V.; Terechova, T.; Boffetta, P.; et al. Alcohol and cause-specific mortality in Russia: A retrospective case-control study of 48,557 adult deaths. Lancet 2009, 373, 2201-2214. [CrossRef]

24. Khan, N.; Mukhtar, H. Tea Polyphenols in Promotion of Human Health. Nutrients 2018, 11, 39. [CrossRef]

25. Higdon, J.V.; Frei, B. Coffee and health: A review of recent human research. Crit. Rev. Food Sci. Nutr. 2006, 46, 101-123. [CrossRef]

26. Tome-Carneiro, J.; Visioli, F. Polyphenol-based nutraceuticals for the prevention and treatment of cardiovascular disease: Review of human evidence. Phytomedicine 2016, 23, 1145-1174. [CrossRef]

27. Grosso, G.; Marventano, S.; Giorgianni, G.; Raciti, T.; Galvano, F.; Mistretta, A. Mediterranean diet adherence rates in Sicily, southern Italy. Public Health Nutr. 2014, 17, 2001-2009. [CrossRef]

28. Raber, M.; Baranowski, T.; Crawford, K.; Sharma, S.V.; Schick, V.; Markham, C.; Jia, W.; Sun, M.; Steinman, E.; Chandra, J. The Healthy Cooking Index: Nutrition Optimizing Home Food Preparation Practices across Multiple Data Collection Methods. J. Acad. Nutr. Diet. 2020. [CrossRef]

29. Mills, S.; White, M.; Brown, H.; Wrieden, W.; Kwasnicka, D.; Halligan, J.; Robalino, S.; Adams, J. Health and social determinants and outcomes of home cooking: A systematic review of observational studies. Appetite 2017, 111, 116-134. [CrossRef]

30. Reneer, Z.B.; Ross, T.M. H2 influenza viruses: Designing vaccines against future H2 pandemics. Biochem. Soc. Trans. 2019, 47, 251-264. [CrossRef]

31. Alvarez-Galvez, J.; Salinas-Perez, J.A.; Montagni, I.; Salvador-Carulla, L. The persistence of digital divides in the use of health information: A comparative study in 28 European countries. Int. J. Public Health 2020. [CrossRef]

32. Tsuboi, S.; Yoshida, H.; Ae, R.; Kojo, T.; Nakamura, Y.; Kitamura, K. Selection bias of Internet panel surveys: A comparison with a paper-based survey and national governmental statistics in Japan. Asia Pac. J. Public Health 2015, 27, NP2390-NP2399. [CrossRef]

(C) 2020 by the authors. Licensee MDPI, Basel, Switzerland. This article is an open access article distributed under the terms and conditions of the Creative Commons Attribution (CC BY) license (http://creativecommons.org/licenses/by/4.0/). 